\title{
Validation of a New Measure of Concept of a Good Death
}

\author{
CAROLYN E. SCHWARTZ, Sc.D., ${ }^{1}$ KATHLEEN MAZOR, Ed.D., ${ }^{2}$ JANE ROGERS, Ph.D., ${ }^{3}$ \\ YUNSHENG MA, M.P.H., Ph.D., ${ }^{1}$ and GEORGE REED, Ph.D. ${ }^{1}$
}

\begin{abstract}
Background: The concept of a good death is central to end-of-life care research. Despite its importance and the high interest in the topic, there are few measures currently available for use in clinical research.

Purpose: The present work describes the development and testing of a set of items intended to measure the importance of several components posited to be critical to the concept of a good death. It is intended for use with health care providers and lay people in the context of end-of-life care research and education.

Population: Four cohorts $(n=596)$ were recruited to participate, representing two helping profession disciplines, nonhelping professionals, and a range of ages, specifically: (1) undergraduate medical students; (2) master's degree students in nursing; (3) graduate students from the life sciences; and (4) practicing hospice nurses.

Methods: Participants completed self-report questionnaires at baseline and retest. Psychometric analyses included item frequency distributions, factor analysis, $\alpha$ reliability, intraclass correlation, and measures of association.

Results: The new Concept of a Good Death measure demonstrated good item frequency distributions, acceptable internal consistency reliability, and test-retest stability. Its factor structure revealed that three distinct domains are measured, reflecting the psychosocial/spiritual, physical, and clinical aspects of a good death. An examination of patterns of correlations showed differential associations with death anxiety, spiritual beliefs and practices, anxious mood, and sociodemographic characteristics.

Conclusions: The new Concept of a Good Death instrument appears to measure three distinct factors which people consider important to a Good Death. Ratings of the importance of these factors are reliable and valid. The instrument has the advantage of being a brief, selfreport index for use in end-of-life care research.
\end{abstract}

\footnotetext{
${ }^{1}$ Division of Preventive and Behavioral Medicine, Department of Medicine, University of Massachusetts Medical School, Worcester, Massachusetts.

${ }^{2}$ Meyers Primary Care Institute, University of Massachusetts Medical School and Fallon Healthcare System, Worcester, Massachusetts.

${ }^{3}$ Division of Research and Evaluation, Office of Medical Education, University of Massachusetts Medical School, Worcester, Massachusetts.
} 


\section{INTRODUCTION}

$\mathbf{T}$ HERE HAS BEEN A VAST and longstanding interest in the concept of a "good death" across disciplines over the past several decades. A recent MEDLINE search revealed that 121 articles had been published between 1966 and July 2002 for which "good death" was a keyword. These articles, published in medical and nursing journals, highlighted not only the interest and importance of the construct, but also the need for well-validated measures of the construct as an integral part of evaluating quality of care at the end of life. ${ }^{1}$ The purpose of the present work was to describe a new instrument for the measurement of the dimensions that comprise one's concept of a good death. This instrument was initially intended for use with health care provider trainees (i.e., medical students and nursing students) to evaluate how their concept of a good death changes over the course of training. It could also be used with practicing health care providers and lay people in the context of research to improve the quality of care at the end of life, and to evaluate the impact of medical curriculum to teach palliative care.

Past research on concept of a good death has revealed that distinct concepts are held by patients, health care providers, and family members. For example, some research suggests that patients are more focused on the psychosocial rather than clinical aspects of dying, such as not being a burden, loss of control, and strengthening relationships with loved ones, rather than physical or psychological symptoms. ${ }^{1,2}$ More recent research suggests that patients focus on a broad range of biomedical, existential, relationship, and communication issues, whereas physicians are more oriented toward a biomedical perspective. $^{3-5}$ These differences in perspective between patient and physician may be a function of role, and thus changeable when physicians become patients or vice versa. Alternatively, the differences in perspectives may relate to the medical school training itself, as suggested by recent work by Walden-Galuszko et al. ${ }^{6-7}$ reporting that first-year medical students' concept of a good death was traditional (i.e., dying at home and surrounded by loved ones) whereas medical professionals who were further along in their training conceptualized a good death as fast, sudden, and with good symptom control. Other factors that have been found to influence one's concept of a good death are having witnessed someone else's death, ${ }^{8}$ one's cultural heritage, ${ }^{9,10}$ having an accurate assessment of one's prognosis, ${ }^{11}$ having an accurate understanding of the utility of life-sustaining treatments for one's actual situation, ${ }^{12}$ and having engaged in advance care planning. ${ }^{13}$ Thus, one's concept of a good death may be changeable with time, role, and experience. Accordingly, having information on the stability of the concept over a short period of time would be useful for understanding the clinical significance of conceptual changes over more extended time frames.

Because most research on concept of a good death has utilized qualitative methods (for example, see Hanson et al. ${ }^{14}$ ), there are few formal measures of concept of a good death. There are guidelines for measuring the concept, ${ }^{1}$ and some helpful models for conceptualizing a good death. One model proposed by Patrick and colleagues ${ }^{15}$ suggests that an evaluation of the quality of dying and death be based on the congruence between a person's preferences and their actual experience, as reported by others, after adjusting for circumstances surrounding death that may prevent following the patient's preferences. Another model, proposed by Stewart and colleagues, ${ }^{16}$ considers quality of dying in a matrix that includes the patient/family context, the structure of care, the process of care, satisfaction with care, and quality and length of life. A few formal measures have emerged in the past few years to assess good death, including an attribute checklist, ${ }^{3}$ a brief, objective observer-assessed tool, ${ }^{17}$ and a questionnaire to assess the quality of dying and death from the perspective of family members after death. ${ }^{18}$ The research generated using these existing methods have led to interesting insights on concept of a good death, but have not established the psychometric reliability or validity of the measures. We thus were unable to focus on construct validity utilizing the standard approach of comparing scores from our new measure with those of an existing, validated measure. Consequently, we focused on evaluating patterns of association between the scores resulting from our measure and other constructs that we believed would be related to Concept of a Good Death.

Our aim for this new measure is to be able to apply it toward a variety of studies aimed at improving quality of life at the end of life. These studies would include comparisons of different groups of health professionals, both in training 
and in the field. It would also include lay people, who may be patients themselves, family members of patients, or people in the community who are the target for community outreach educational efforts. Accordingly, the present study included four cohorts of participants: medical students, nursing students, graduate students in a nonhealth profession discipline, and hospice nurses. This sampling scheme was intended to ensure representation across two helping profession disciplines, and to introduce variability in age, career choice, and experience with death.

\section{METHODS}

\section{Subjects and procedure}

This study was designed both to validate the new measure of Concept of a Good Death and to consider differences between known groups with regard to this construct, the latter of which will be reported elsewhere. Accordingly, four cohorts of volunteers were recruited for this study: (1) undergraduate medical students from the University of Massachusetts Medical School; (2) master's degree students in nursing from the University of Massachusetts Graduate School of Nursing; (3) graduate students from four interdisciplinary life sciences programs (i.e., molecular and cellular biology; neuroscience and behavior; organismic and evolutionary biology; plant biology) at the University of Massachusetts Amherst; and (4) practicing hospice nurses. Potential participants were recruited via the administrative office of their educational program or hospice, for students and practicing hospice nurses, respectively. All participants completed the questionnaires, and blinded forms were then sent to the University of Massachusetts Medical School Office of Medical Education, where the forms were scanned into an electronic database for analysis. This project was deemed exempt from review by the Human Subjects Committee. Accordingly, informed consent was inferred by dint of the participant's returning the completed forms.

\section{Design}

Two waves of data collection were implemented for this study. The first wave comprised cross-sectional data from 390 medical students as part of a larger data collection effort led by the Office of Medical Education. This questionnaire included the Concept of a Good Death measure and open-ended questions about intended specialty, prior experience with death, and religion. The second wave of data collection comprised collecting baseline and retest data from the four cohorts of participants. In this wave, the abovementioned questionnaires were supplemented with questionnaires intended for construct validation (described below under Measures). The retest packet was to be distributed and collected 1 to 2 weeks later, and did not include the construct validity questionnaires. Consequently, sample sizes for the analyses vary. Data from 596 participants (451 medical students, 47 nursing students, 48 life science students, and 50 hospice nurses) were available for factor analyses. Data from a subset of 194 participants (61 medical students, 40 nursing students, 43 life science students, and 50 hospice nurses) with complete data were available for evaluating the patterns of correlations, internal consistency, and test-retest stability of the measure.

\section{Measures}

The Concept of a Good Death measure consists of 17 descriptive statements of the various components that might be considered important to one's concept of a good death. The work sought to build on the concepts of Walden-Galuszko ${ }^{6-7}$ of a traditional versus modern death, and to include dimensions that are increasingly recognized as important at the end of life, including spiritual peace, acceptance, closure with family and friends, pain, etc. The individual items were gleaned from discussions with clinicians as well as the published lay and professional literature. $6,7,17,20-24$ The item pool was reduced in further discussions with our own research team to eliminate redundant items. The new measure asks respondents to indicate the importance (not necessary [1] to essential [4]) of the 17 distinct characteristics to their concept of a good death (see Table 1 for items and Appendix A for copy of measure). Subscale scores are created by summing the items within the subscale.

Because the construct of interest (i.e., Concept of a 'Good Death' is not one for which there are multiple existing measures or for which one would expect high associations with other quality-of-life constructs, ${ }^{25}$ we did not examine construct validity per se but rather explored patterns of associations between the new measure and 


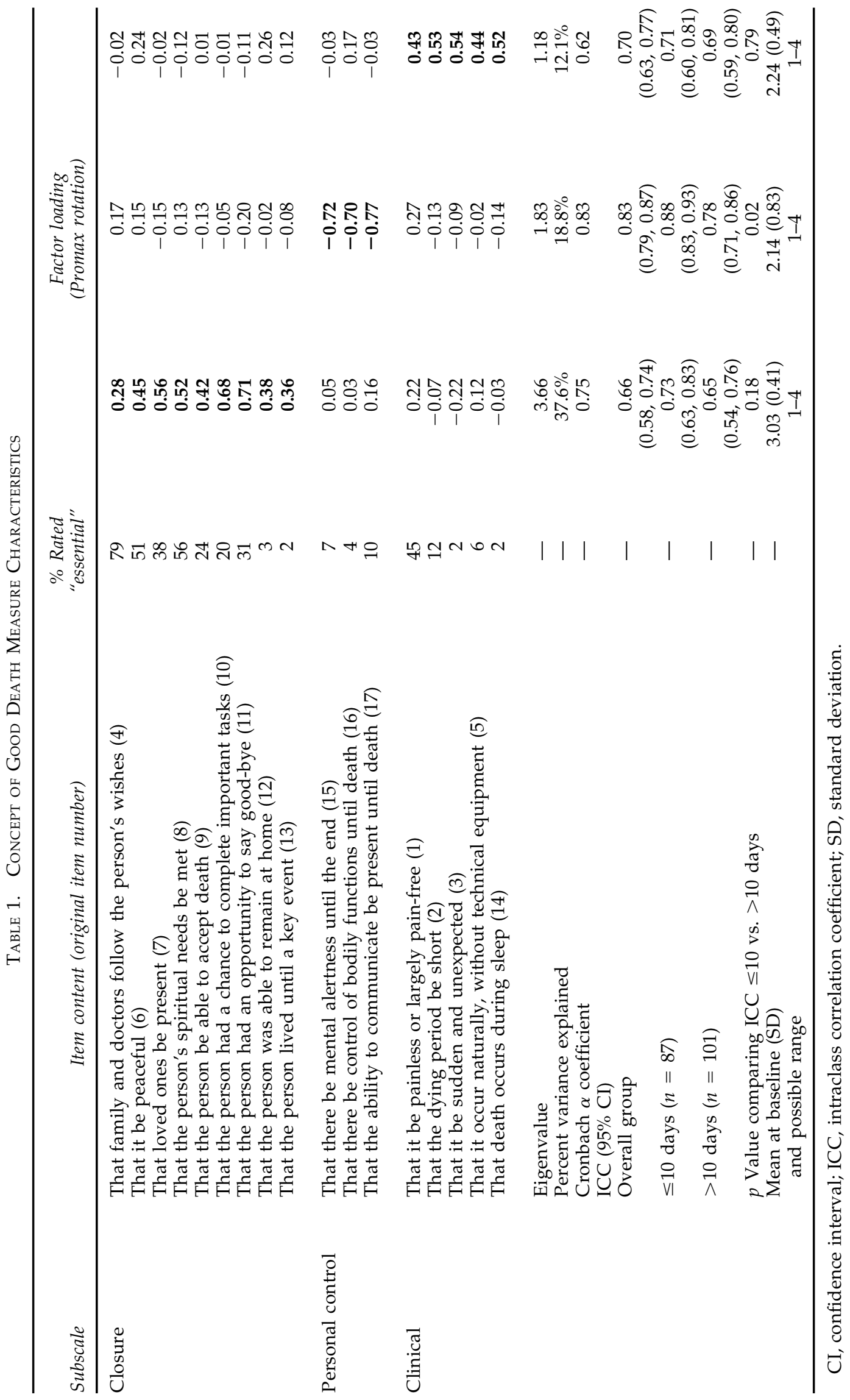


four standardized scales to provide descriptive evidence of the construct. The first scale, the Death Attitude Profile-Revised, ${ }^{26}$ is a 32-item measure that includes subscales addressing death acceptance and avoidance. Within the death acceptance subscales, neutral acceptance measures the view of death as a reality that is neither feared nor welcomed; approach acceptance measures the view of death as a gateway to a happy afterlife; and escape acceptance measures the view of death as an escape from a painful existence. Within the avoidance subscales, the fear of death subscale measures negative thoughts and feelings about the state of death and the process of dying, whereas death avoidance assesses the extent to which a person avoids thinking or talking about death in order to reduce death anxiety. Items are rated on a seven-point Likert scale ranging from "strongly agree" to "strongly disagree." The measure has demonstrated reliability and validity, and there are established gender- and age-related norms. ${ }^{26}$ The second scale, the Tension-Anxiety subscale of the Profile of Mood States (POMS), ${ }^{27}$ is a nine-item adjective checklist with Likert scaled items that asks respondents to indicate how much they have experienced these feelings in the past week (not at all [1] to extremely [5]). Three subscales from the brief form of the Ryff Happiness Scale ${ }^{28}$ were included to look at associations with measures of existential well-being. Personal growth assesses a sense of continued growth and development as a person; purpose in life assesses the belief that one's life is purposeful and meaningful; positive relations with others assess the possession of quality relations with others. ${ }^{28}$ Each subscale contains three items, and asks respondents to endorse positively and negatively worded statements reflecting the construct on a Likert scale (strongly disagree [1] to strongly agree [6]). Importance of spiritual practice was measured using one Likert-scaled item (not at all [1] to a great deal [4]). Additionally, two aspects of spiritual well-being were assessed by the Brief Spiritual Beliefs Inventory. ${ }^{29}$ This 15 -item scale contains two subscales. The beliefs and practices subscale assess religious believes and practices, as well as belief in a supreme being. The social support from the religious community assesses the extent to which one experiences social support from one's religious or spiritual community. Finally, sociodemographic characteristics (age, gender, ethnicity, religion) and training/ experience (year of training, experience with dying patients, and specialty) were queried.

\section{Statistical analysis}

Item frequency distributions were examined to ascertain whether score distributions sampled the full range of anchors. Factor analysis with a promax rotation was done on the ratings of items from the Concept of a Good Death measure. Internal consistency reliability was evaluated using Cronbach $\alpha,{ }^{30}$ and test-retest stability was assessed with the intraclass correlation coefficient. ${ }^{31}$ Patterns of association between the Concept of a Good Death subscales and other measures were evaluated with Pearson correlation coefficients, $t$ tests, and analysis of variance, as indicated in Table 2.

\section{RESULTS}

\section{Sample}

There were a total of 596 participants in this study, including 451 medical students, 47 nursing students, 48 biology students, and 50 hospice nurses. Sixty-three percent of the participants were female, and $83 \%$ were Caucasian. The mean age was 29.8 years (standard deviation [SD] 8.3), with a range from 21.8 to 60.9 .

\section{Item frequency distributions}

An examination of the item frequency distributions, means, and standard deviations supported the idea that respondents used the full range of possible responses. Table 1 shows the percent of respondents who endorsed the items as "essential." It should be noted that one item, "That family and doctors follow the person's wishes," was considered essential by a large proportion of the sample $(79 \%)$, and seven items were considered essential by a small proportion of the sample. While this relative lack of variability may not be ideal from a psychometric perspective, we decided to retain the items in the interest of content validity because they are generally considered central to the general construct of Good Death.

\section{Factor analyses}

Results of the factor analysis suggested three distinct domains measured by this set of items. 
Table 2. Patterns of Associations with Concept of Good Death Measure

\begin{tabular}{|c|c|c|c|}
\hline Measure & Closure & Personal control & Clinical \\
\hline \multicolumn{4}{|l|}{ Death Anxiety Profile ${ }^{\mathrm{a}}$} \\
\hline Fear of death & $0.06(0.40)$ & $0.25(0.00004)$ & $0.02(0.79)$ \\
\hline Death avoidance & $-0.02(0.83)$ & $0.24(0.0007)$ & $0.14(0.06)$ \\
\hline Approach-acceptance & $0.18(0.02)$ & $-0.19(0.009)$ & $0.09(0.19)$ \\
\hline Escape-acceptance & $0.14(0.06)$ & $-0.03(0.65)$ & $0.19(0.009$ \\
\hline Neutral-acceptance & $-0.002(0.98)$ & $-0.10(0.15)$ & $0.08(0.27)$ \\
\hline \multicolumn{4}{|l|}{ Profile of Mood States ${ }^{a}$} \\
\hline Tension-anxiety & $-0.03(0.073)$ & $0.21(0.003)$ & $0.02(0.77)$ \\
\hline \multicolumn{4}{|l|}{ Ryff Happiness Scale ${ }^{a}$} \\
\hline Personal growth & $0.11(0.13)$ & $-0.006(0.94)$ & $-0.03(0.65)$ \\
\hline Purpose in life & $-0.003(0.67)$ & $-0.01(0.88)$ & $-0.05(0.51)$ \\
\hline Positive relations with others & $0.15(0.03)$ & $-0.15(0.04)$ & $0.11(0.14)$ \\
\hline \multicolumn{4}{|l|}{ Systems of Belief Inventory ${ }^{a}$} \\
\hline Beliefs and practices & $0.24(0.001)$ & $-0.14(0.05)$ & $0.12(0.11)$ \\
\hline $\begin{array}{l}\text { Social support from religious } \\
\text { community }\end{array}$ & $0.25(0.0004)$ & $-0.18(0.01)$ & $0.06(0.45)$ \\
\hline Age $^{a}$ & $0.19(0.02)$ & $-0.31(<0.0001)$ & $0.20(0.01)$ \\
\hline \multicolumn{4}{|l|}{ Gender $^{\mathrm{b}}$ Mean (SD) } \\
\hline Male (38) & $2.86(0.43)$ & $2.25(0.77)$ & $2.11(0.41)$ \\
\hline Female (153) & $3.07(0.40)$ & $2.11(0.85)$ & $2.27(0.51)$ \\
\hline$t$ statistic ( $p$ value) & $-2.6(0.005)$ & $0.84(0.40)$ & $-1.8(0.07)$ \\
\hline \multicolumn{4}{|l|}{ Race/ethnicity } \\
\hline Caucasian (159) & $3.05(0.41)$ & $2.05(0.80)$ & $2.23(0.48)$ \\
\hline Others (32) & $2.97(0.43)$ & $2.63(0.83)$ & $2.28(0.57)$ \\
\hline$t$ statistic ( $p$ value) & $0.92(0.36)$ & $-3.68(0.0003)$ & $-0.46(0.65)$ \\
\hline \multicolumn{4}{|l|}{$\begin{array}{l}\text { Importance of spiritual } \\
\text { practice }\end{array}$} \\
\hline Not at all (31) & $2.82(0.40)$ & $2.46(0.80)$ & $2.23(0.44)$ \\
\hline A little (43) & $3.02(0.40)$ & $2.36(0.86)$ & $2.25(0.56)$ \\
\hline Somewhat (52) & $3.07(0.41)$ & $2.08(0.83)$ & $2.28(0.50)$ \\
\hline A great deal (55) & $3.12(0.42)$ & $1.87(0.72)$ & $2.21(0.50)$ \\
\hline$F$-statistic ( $p$ value) & $3.8(0.01)$ & $4.84(0.003)$ & $0.13(0.94)$ \\
\hline
\end{tabular}

${ }^{a}$ Values presented were Pearson correlation coefficients and $p$ values to test $\mathrm{H}_{0}: \rho=0$ in parentheses.

${ }^{\mathrm{b}}$ Comparisons were done using $t$ tests. Values presented are mean scores and standard deviation in parenthesis.

The three factors explained approximately $69 \%$ of the variance in the data (Table 1). The first factor contained nine items. Review of the item content for the items loading on this factor reveal that the majority of the items have to do with psychosocial and spiritual aspects of dying, therefore this factor is referred to as closure. It had high internal consistency, and explained approximately $38 \%$ of the variance. The second factor contained three items, addressing mental alertness, ability to communicate, and control of bodily functions, therefore this factor is referred to as personal control. It had high internal consistency and ex- plained approximately $19 \%$ of the variance. The third factor contained five items that focused on the clinical or biomedical aspects of the dying experience. This factor is therefore is referred to as clinical. It had moderate internal consistency and explained approximately $12 \%$ of the variance. The inter-subscale correlations were small to moderate in magnitude (closure and personal control $r=0.20$; closure and clinical criteria $r=$ 0.38 , and personal control and clinical criteria $r=$ 0.31 ), suggesting that they measure related but relatively independent domains within concept of a good death. 


\section{Test-retest stability}

Intraclass correlation coefficients (ICC) suggested moderately high stability in the closure, personal control, and clinical criteria subscale scores over the retest period (ICC $=0.66,0.83$, and 0.70 , respectively; mean $=14.7$ days, $\mathrm{SD}=$ 12.5 ; range, $1-65$ days). When analyses were stratified by the amount of time between baseline and retest instances, we found that test-retest stability increased by 2 to 10 points when the retest period was 10 days or fewer, although the overall group's ICCs were still contained in the shorter retest subgroup's 95\% confidence interval (CI) (Table 1).

\section{Patterns of associations}

Table 2 presents the coefficients of association between the three new subscales, comparison measures, and sociodemographic characteristics. Closure was associated with approach-acceptance, positive relations with others, spiritual beliefs and practices, spiritual support from the religious community, being older, being female, and reporting that spiritual practice was more important. Personal control was associated with fear of death, death avoidance, approach-acceptance, tense-anxious mood, not endorsing spiritual beliefs and practices, not endorsing spiritual support from the religious community, being younger, being an ethnicity other than Caucasian, and reporting that spiritual practice was less important. Clinical criteria was associated with escape-acceptance and being older. All of these coefficients were small-to-moderate in magnitude, suggesting that the new subscales measure constructs distinct from but conceptually related to death anxiety, anxious mood, existential well-being, and spirituality. The subscales were differentially associated with age, gender, and ethnicity, suggesting that concept of a good death varies in the population according to experience and cultural background.

\section{DISCUSSION}

The results of the present study suggest that the items that comprise the Concept of a Good Death instrument measure three distinct domains. Higher scores on a subscale reflect increasing importance of that domain of Concept of a Good Death. The first, closure, reflects the psychosocial or spiritual aspects of good death, and is associated with belief in an afterlife experience, having meaningful social support, spiritual beliefs and practice, and being older and female. The second domain, personal control, focuses on the more physical aspects of the dying experience, and is associated with more negative attitudinal and mood indicators, and with not having a spiritual or religious connection. It was also associated with being younger and from a minority group. The third domain, clinical, reflects the more biomedical aspects of a good death, and was associated with a perspective that death is a relief from the negative aspects of life on earth, and being older. It should be noted that the associations with age reported above may reflect group membership rather than age, because hospice nurses tended to be older than nursing students, biology graduate students, and medical students (in that order). Results of the reliability analyses suggest that scores based on each of the three sets of items have acceptable internal consistency reliability and test-retest stability.

These three subscales are likely to be useful for studying differences between various healthcare providers and lay populations (e.g., dying patients, the general public, etc.), and for evaluating change over time. Because the measure demonstrates high test-retest stability, especially when the retest is given within 10 days of the baseline, the measure is likely to be sensitive to meaningful changes in concept of a good death over time and experience, and thus will be a useful tool for a broad range of studies related to attitudes toward end of life. We are optimistic that the psychometric properties described herein would be comparable on these other populations but note that this remains an empirical question.

In general, we found that the items contained in the Concept of a Good Death measure demonstrated variability in response (i.e., most items did not elicit the same endorsement from the study participants). There were several exceptions, however. The item, "That family and doctors follow the person's wishes," was rated as essential by $79 \%$ of the sample. The items "remained at home," "lived until a key event," "mental alertness until the end," "control of bodily functions," "sudden and unexpected," "without technical equipment," and "occurs during sleep" were rated as essential by $2 \%$ to $7 \%$ of the sample. While some approaches to instrument 
development would suggest omitting items with lower variance, given the purpose of this instrument, a measure that did not include such items would seem to suffer in content validity. We believe that such an item will prove useful in studies of advance care planning interventions (e.g., congruence between providers and patients on the importance of following a patient's expressed wishes), medical care curriculum (i.e., a clearer understanding of the dying experience), other patient groups (e.g., older patients, family members after death, hospice patients) and other studies of quality of care at the end of life (e.g., dying at home if this is important to the patient).

Given the relevance of recent work on good death, it would be useful to provide a brief comparison of the concepts measured in the Concept of a Good Death measure and those of Steinhauser et al. ${ }^{3}$ and Cohen et al. ${ }^{17}$ Approximately $60 \%$ of the items in the Steinhauser measure are represented in our measure, with the remaining items reflecting non-pain symptom control, specific aspects of social support, predictability, health care provider approachability, and not being a burden. Because Dr. Cohen was one of the clinicians consulted during our item development phase, it is not surprising that the Cohen quality of dying Apgar overlaps almost completely with our measure. It should be noted, however, that some non-pain symptoms were covered more specifically in the Apgar than in our measure. Concepts addressed in our measure that were not covered in either of the other measures were living until a key event, control of bodily functions, ability to communicate, shortness of the dying experience, suddenness, and occurring during sleep. Thus, the new Concept of a Good Death measure is a brief measure that covers many of the same concepts as these other measures, but does not address all aspects of non-pain symptom control. Future research might explore interrelationships among the three measures in health care providers, patients, and caregivers.

In summary, the new Concept of a Good Death measure appears to yield scores that are reliable and valid in the samples studied here, and has the advantage of being a brief, self-report index for use in a broad range of populations. It is our hope that clinical researchers will be able to use this new measure to advance the field of end-oflife care research.

\section{ACKNOWLEDGMENTS}

This work was supported in part by the Macy Initiative in Health Communication at the University of Massachusetts Medical School. We would also like to acknowledge Lewis Cohen, M.D., for helpful discussions early in the planning of this project; David Clive, M.D., and Marjorie Clay, Ph.D., for their interest and support that made this project possible and feasible; Hilery Woodcock, Susan Capistran, Penny Jaques, Linda Witt, Mary Kay Alexander, Mary Whalen, Sally Okun, and Laura Sefton for assistance with data collection, and Lorna Chiasson and Kathrine Gendreau for data management support.

\section{REFERENCES}

1. Emanuel EJ, Emanuel LL: The promise of a good death. Lancet 1998:351(suppl II):21-29.

2. Singer PA, Martin DK, Kelner M: Quality end-of-life care: Patient's perspectives. JAMA 1999;281:163-168.

3. Steinhauser KE, Christakis NA, Clipp EC, McNeilly M, McIntyre L, Tulsky JA: Factors considered important at the EOL by patients, family, physicians, and other care providers. JAMA 2000;284:2476-2482.

4. Emanuel LL, Alpert HR, Baldwin DC, Emanuel EJ: What terminally ill patients care about: Toward a validated construct of patients' perspectives. J Palliat Med 2000;3:419-431.

5. Payne SA, Langley-Evans A, Hillier R: Perceptions of a "good" death: A comparative study of the views of hospice staff and patients. Palliat Med 1996;10: 307-312.

6. Walden-Galuszko KD, Majkowicz M, and Trzebiatowska IA: A comparative study of the views of the medical staff, medical students and non-health professionals [abstract]. Acta Oncolog 1998.

7. Walden-Galuszko KD, Majkowicz M, Trzebiatowska IA. Pojêcie dobrej úmierci u peronelu medycznego. Psychoonkologia 1997;1:39-43.

8. Payne S, Hillier R, Langley-Evans A, Roberts T: Impact of witnessing death on hospice patients. Soc Sci Med 1996;43:1785-1794.

9. Kawaga-Singer ML: Diverse cultural beliefs and practices about death and dying in the elderly. Gerontol Geriatr Educ 1994;15:101-116.

10. Koenig BA, Gates-Williams J: Understanding cultural differences in caring for dying patients. West J Med 1995;163:244-249.

11. Chochinov HM, Tataryn DJ, Wilson KG, Enns M, Lander S: Prognostic awareness and the terminally ill. Psychosomatics 2000;41:500-504.

12. Norton SA, Bowers BJ: Working toward consensus: Providers' strategies to shift patients from curative to 
palliative treatment choices. Res Nurs Health 2001;24: 258-269.

13. Swartz RD, Perry E: Advance directives are associated with "good deaths" in chronic dialysis patients. J Am Soc Nephrol 1993;3:1623-1630.

14. Hanson LC, Henerson M, Menon M: As individual as death itself: A focus group study of terminal care in nursing homes. J Palliat Med 2002;5:117-125.

15. Patrick DL, Engelberg RA, Curtis JR: Evaluating the quality of dying and death. J Pain Sympt Manage 2001;22:717-726.

16. Stewart AL, Teno J, Patrick DL, Lynn J: The concept of quality of life of dying persons in the context of health care. J Pain Sympt Manage 1999;17:93-108.

17. Cohen LM, Poppel DM, Cohn GM, Reiter GS: A very good death: Measuring quality of dying in end-stage renal disease. J Palliat Med 2001;4:167-172.

18. Curtis JR, Patrick DL, Engelberg RA, Norris K, Asp C, Byock I: A measure of the quality of dying and death: Initial validation using after-death interviews with family members. J Pain Sympt Manage 2002;24: 17-31.

19. Steinhauser KE, Clipp EC, McNeilly M, Christakis NA, McIntyre LM, Tulsky JA: In search of a good death: Observations of patients, families, and providers. Ann Intern Med 2000;132:825-832.

20. Byock I: Dying Well: The Prospect for Growth at the End of Life. Riverhead Books: New York, 1997.

21. Cohen L: Family Follow-up Interview. Greenwall Foundation, 2000.

22. Cohen LM, Germain MJ, Poppel DM, Woods AL, Pekow PS, Kjellstrand CM: Dying well after discontinuing life support treatment of dialysis. Arch Intern Med 2000;160:2513-2518.

23. Moss AH: Measuring the quality of death. J Palliat Med 2001;4:149-151.
24. Hinton J: The progress of awareness and acceptance of dying assessed in cancer patients and their caring relatives. Palliat Med 1999;13:19-35.

25. Cronbach LJ, Meehl PE: Construct Validity in Psychological Tests. Psychol Bull 1955;52:281-302.

26. Wong P, Reker G, Gesser G: Death Attitude ProfileRevised. In: Neimeyer RA (ed) Death anxiety handbook: Research, implementation, and application. Series in death, education, aging, and health care. Taylor \& Francis: Philadelphia, PA, 1999.

27. McNair DM, Lorr M, Droppleman LF: EdITS Manual: Profile of Mood States. San Diego, CA: Educational and Industrial Testing Service, 1971.

28. Ryff CD, Keyes CLM: The structure of psychological well-being revisited. J Person Soc Psychol 1995;69: 719-727.

29. Holland JC, Kash KM, Passik S, Gronert MK, Sison A, Lederberg M, Russak SM, Baider L, Fox B: A brief spiritual beliefs inventory for use in quality of life research in life-threatening illness. Psychooncology 1998;7:460-469.

30. Cronbach LJ: Coefficient alpha and the internal structure of tests. Psychometrika. 1951;16:297-334.

31. Kramer MS, Feinstein AR: Clinical biostatistics LIV. The biostatistics of concordance. Clin Pharmacol Ther 1981;29:111-123.

Address reprint requests to: Carolyn E. Schwartz, Sc.D. 31 Mitchell Road Concord, MA 01742

E-mail: carolyn.schwartz@deltaquest.org 
Appendix A. The Concept of a Good Death Measure

Please indicate how important each of the following is to your conception of a "good" death.

Not

necessary

Desirable

Important

Essential

1. That it be painless or largely

1

2

3

pain-free.

2. That the dying period be short.

3. That it be sudden and unexpected.

4. That family and doctors follow the person's wishes.

5. That it occur naturally, without technical equipment.

6. That it be peaceful.

7. That loved ones be present.

8. That the person's spiritual needs be met.

9. That the person is able to accept death.

10. That the person had a chance to complete important tasks.

11. That the person had an opportunity to say "good-bye"

12. That the person was able to remain at home.

13. That the person lived until a key event.

14. That death occurs during sleep.

15. That there be mental alertness until the end.

16. That there be control of bodily functions until death.

17. That the ability to communicate be present until death.

$\begin{array}{llll}1 & 2 & 3 & 4 \\ 1 & 2 & 3 & 4 \\ 1 & 2 & 3 & 4 \\ 1 & 2 & 3 & 4 \\ 1 & 2 & 3 & 4 \\ 1 & 2 & 3 & 4 \\ 1 & 2 & 3 & 4 \\ 1 & 2 & 4 \\ 1 & 2 & 3 & 4 \\ 1 & 2 & 3 & 4 \\ 1 & 2 & 3 & 4 \\ 1 & 2 & 3 & 4 \\ 1 & 2 & 3 & 4 \\ 1 & 2 & 3 & 4 \\ 1 & 2 & 4 \\ 1 & 2 & 3 & 4 \\ 1 & 2 & 3 & \\ 1 & 2 & 3 & 4\end{array}$

